
organizes series of lectures on selected topics of contemporary physics for schoolteachers. Also, biannually it organizes the Croatian Symposium on Physics Education. D for Industrial and Applied Physics organizes workshops and round tables at which physicists from academic community and industry meet. D for Promotion of Physics presents the CPS projects on Croatian TV channels, radio stations and in printed and electronic newspapers. The CPS portal is regularly updated with news covering the CPS and EPS actions and events in both Croatian and English. In 2010, the CPS portal registered 27114 visits from 84 countries, out of which 25515 were from Croatia. The most popular project of the Student D is the project named Physics Express, which was initiated during the World Year of Physics in 2005. In the framework of this project, our students visit schools all around Croatia and promote physics by presenting simple experiments to show physics in daily life and by establishing a direct communication with school students. Since 2005, almost 5000 elementary and high school students in about 100 schools have attended the Physics Express presentations (Picture 3).

Since 1992 the Society edits two international peerreviewed scientific journals FIZIKA A and FIZIKA B in which original research articles covering all branches of physics and its applications, including teaching and history of physics are published in English. The actual tendencies and strong competition in global scientific publishing, and a negative trend of the financial support, raised intense discussions whether to continue to publish national journals or to close them and merge to one of the European Physical Journals editions. As a recent outcome of thorough discussions inside CPS and consultations with EPJ publishers, the Managing Board decided to merge the journal Fizika A to EPJPlus, the electronic journal that has been released in January 2011. In cooperation with the Croatian Mathematical Society, CPS also edits a popular magazine entitled "Mathematical-Physical Journal", founded in 1950, for elementary (age 12-14) and high school students (age 14-18) and physics and mathematics teachers. Each volume (comprising four issues a year) contains articles covering various topics in mathematics, physics, astronomy and informatics, information about national and international competitions, reviews of new science books and theoretical problems addressed to curious students.

Other activities of CPS include projects and groups like Electronic-school of Physics (E-school), the Summer School for Young Physicists and Women in Physics. The latter surveys the status of female physicists in academic community, organizes round tables and search for policy priorities improving the specific situations women encounter as compared to men. E-school was established twelve years ago as a web site dedicated to

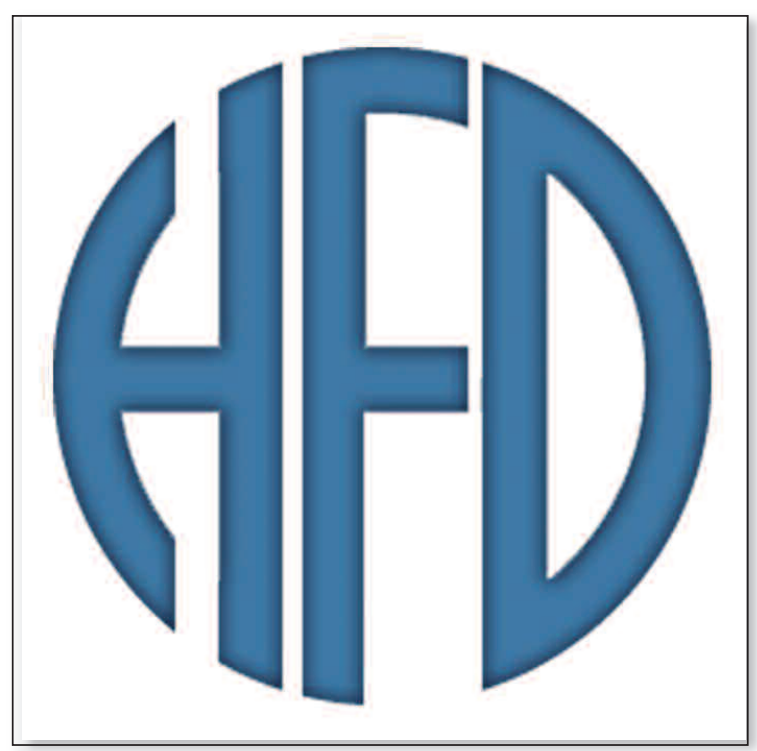

4 FIG. 2:

Logo of Croatian Physical Society. the news in physics, not only for high school students and physics teachers, but also for all individuals interested in physics. In the last three years almost 100 additional Internet pages were created with new educational material. E-school Internet portal registers in average 200 visits per day that is the best sign of how popular and attractive this project is. Further, in cooperation with the Croatian Education and Teacher Training Agency and the Ministry of Science, Education and Sports, the CPS organizes elementary and high school competitions in physics at regional and national levels, and prepares as well the gifted students to participate in the international Physics Olympiad and Young

V FIG. 3: Physics Express visiting an elementary school in Rijeka. Ines Filipas from Physics Express explaining the exercise entitled "Rubens tube", while one of the students is trying to induce the tube standing waves by identifying the right frequency with his voice.

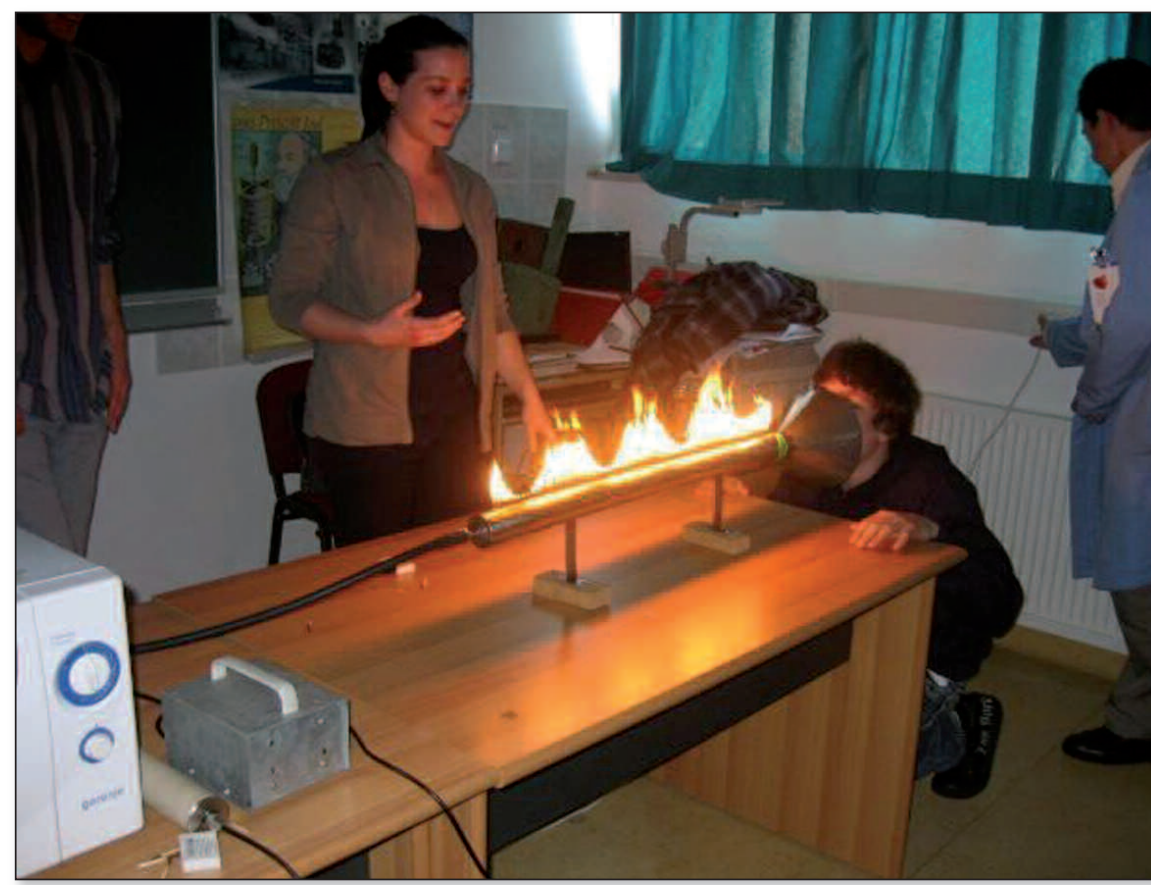




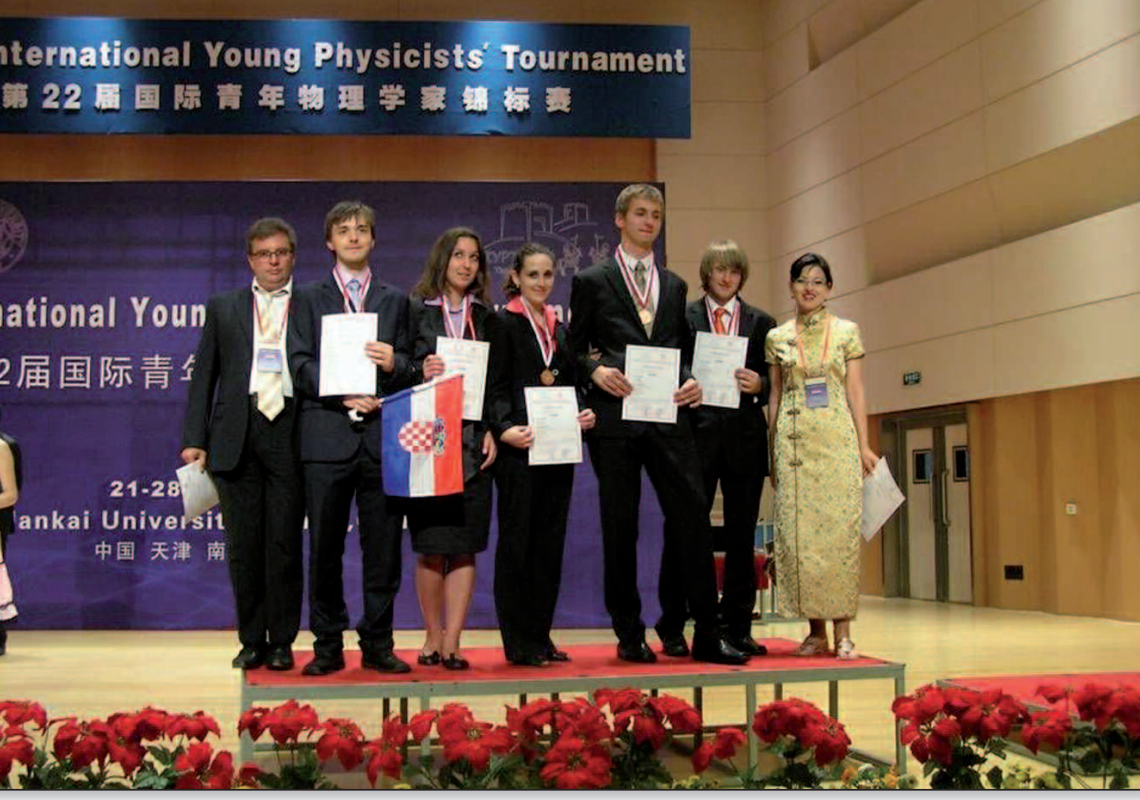

$\Delta$ FIG. 4: Members of the Croatian team (left to right): Damir Klicek (leader), Dino Santl, Lora Grbanovic, Petra Vuckovic, Dino Halusek, Krunoslav Ljaljek and Lidia Saric (leader) at the closing ceremony of the $22^{\text {nd }}$ International Young Physicists' Tournament, 21 - 28 July 2009 which was held in Tianjin, China.

- Physicist's Tournament. The Croatian high school students in both of these competitions usually achieve very good results: winning bronze medals is regular, making us all very proud of them (Picture 4). CPS also organizes each year the Summer School for Young Physicists dedicated to various subjects in physics: the students with the best results at the national competition are invited. CPS considers this event as a kind of reward to students that distinguished themselves and gives them the opportunity to follow the lectures of the best Croatian scientists and participate in the interactive laboratory exercises.

\section{International activities}

As an additional expression of commitment to help promote physics education, CPS took the responsibility to organize three important international events in the last three years: the $21^{\text {st }}$ International Young Physicists' Tournament in 2008, the $24^{\text {th }}$ International Conference of Physics Students in 2009 and the $41^{\text {st }}$ International Physics Olympiad in 2010, the latter being organized in cooperation with the University of Zagreb. The $21^{\text {st }}$ International Young Physicists' Tournament attracted in Trogir teams from 24 countries all over the world. The unique aspect of the Tournament, compared with other contests, is that it constitutes the competition among teams of high school students, instead of individuals. The $24^{\text {th }}$ International Conference of Physics Students in Split had almost 500 students from 22 countries worldwide. It is unique as a physics conference, since it brings students of physics together with only few senior researchers guests. The third event, $41^{\text {st }}$ International Physics Olympiad in 2010 was held in Zagreb. It is an international individual competition for high school students to which participated 370 of them, representing 80 countries from all over the world. We consider that this event was extremely important not only for the Croatian academic community but also for the whole country and we are very grateful to the
Ministry of Science, Education and Sports, the City of Zagreb and the other sponsors from Croatia and Europe (SIF and EPS), for their valuable support without which it would not have been organized.

In coordination with the EPS, the CPS was active in the World Year of Physics in 2005 and is, since 2007 in "The implementation of the Bologna Process into Physics Studies in Europe".

\section{Prospects}

The promotion of physics and sciences becomes more and more a challenge. It is somehow paradoxical to observe a physics decline in public prestige after its historical record all along the 20th century, which demonstrates the importance of basic, curiosity-driven research for economic prosperity and justifies the belief that it should continue. This implies that we all need to pay greater attention to the way Physics should be taught to young people and future generations who have to build the civilization of the 3rd millennium, as well as to work hard achieving better support for research. It is the synergy of improved education and research that guarantees a safe and prosperous future. It is essential to make known to all that physics is a fundamental source of progress in itself as well as in broad areas ranging from energy and environment to medicine and health. CPS is a proud member of European Physical Society and International Union of Pure and Applied Physics. We are confident that in this way and only together we can forge an effective partnership for the benefit of science, education and humankind worldwide. And perhaps most importantly of all we need to understand and feel that physics and scientifically based approach to life represent a basic tool which can help humankind to create a new just and meaningful world.

\section{Acknowledgements}

I thank Vlasta Horvatic for critical reading of the manuscript. The high quality pictures were provided by V. Horvatic, D. Androic, M. Basletic, D. Jelic.

\section{About the Author}

Silvia Tomic is Senior Scientific Advisor at Institute of Physics in Zagreb. She studied physics at University of

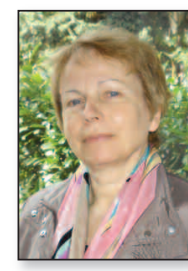
Zagreb and became Docteur d'État ès Sciences Physiques at University ParisSud. Field: condensed matter physics and biological physics. She served as President of CPS 2007-2010 and is CSP representative in SAC of EPJ since 2009.

\section{NOTE}

A full version of this article is published in the bulletin of the Italian Physical Society, Il Nuovo Saggiatore 27, 3-4 (2011). 